\title{
Cellular Morphogenesis in the Saccharomyces cerevisiae Cell Cycle: Localization of the CDC11 Gene Product and the Timing of Events at the Budding Site
}

\author{
SUSAN K. FORD AND JOHN R. PRINGLE \\ Department of Biology, The University of Michigan, Ann Arbor
}

\begin{abstract}
The Saccharomyces cerevisiae CDC3, CDC10, CDC11, and CDC12 genes encode a family of homologous proteins that are not closely related to other known proteins [Haarer BK, Ketcham SR, Ford SK, Ashcroft DJ, and Pringle JR (submitted)]. Temperature-sensitive mutants defective in any of these four genes display essentially identical pleiotropic phenotypes that include abnormal cell-wall deposition and bud growth, an inability to complete cytokinesis, and a failure to form the ring of $10 \mathrm{~nm}$ filaments that normally lies directly subjacent to the plasma membrane in the neck region of budding cells. We showed previously that the CDC3 and CDCl2 gene products localize to the region of the mother-bud neck and are probably constituents of the ring of $10 \mathrm{~nm}$ filaments. We now report the generation of polyclonal antibodies specific for the CDCll product $(\mathrm{Cdcl} \mid \mathrm{p})$ and the use of these antibodies in immunofluorescence experiments with wild-type and mutant cells. The results suggest that Cdcl lp is also a constituent of the filament ring, and thus support the hypothesis that the $S$. cerevisiae $10 \mathrm{~nm}$ filaments represent a novel type of eukaryotic cytoskeletal element. Cdcllp and actin both localize to the budding site well in advance of bud emergence and at approximately the same time, and both proteins also remain localized at the old budding site for some time after cytokinesis. Cdc lip also localizes to regions of cell-wall reorganization in mating cells and in cells responding to purified mating pheromone. Surprisingly, most preparations of affinity purified Cdcl lp-specific antibodies also stained the nuclear and cytoplasmic microtubules. Although this staining probably reflects the existence of an epitope shared by Cdcl $\mathrm{lp}$ and some microtubuleassociated protein, the possibility that a fraction of the Cdcllp is associated with the microtubules could not be eliminated.
\end{abstract}

Key words: Actin function, cell wall, cytoskeleton, fusion proteins, mating, $10 \mathrm{~nm}$ filaments, yeast

\section{INTRODUCTION}

A fundamental problem in cell and developmental biology is to understand the molecular mechanisms that control the generation of cell shape and intracellular three-dimensional organization. The mitotic celldivision cycle of the yeast Saccharomyces cerevisiae includes a variety of morphogenetic events that involve both localized cell-surface changes and the specific positioning of intracellular organelles [Pringle and Hartwell, 1981; Cabib et al., 1982; Pringle et al., 1986]. As in other eukaryotes, cytoskeletal elements, including both microtubules [Byers, 1981; Kilmartin and Adams, 1984; Adams and Pringle, 1984; Huffaker et al., 1988; Jacobs et al., 1988] and the actin system [Kilmartin and Adams, 1984; Adams and Pringle, 1984; Novick and Botstein, 1985; Drubin et al., 1988; Adams et al., 1989; Haarer et al., 1990], are believed to play important roles in these processes.

Yeast cells contain at least one other cytoskeletal element, a highly ordered array of filaments $\sim 10 \mathrm{~nm}$ in diameter that lies directly inside the cytoplasmic membrane in the region of the mother-bud neck [Byers and Goetsch, 1976a; Byers, 1981]. Electron microscopy has suggested that these filaments appear just prior to or coincident with bud emergence and are lost just prior to cytokinesis. Temperature-sensitive mutants defective in any of four different cell-division cycle genes ( $C D C 3, C D C 10, C D C 11$, and $C D C 12$ ) fail to form these filaments at restrictive temperature [Byers and Goetsch, 1976b; Adams, 1984] and display pleiotropic morphogenetic abnormalities including abnormal organization of the cell wall at the base of the bud (no normal chitin ring is formed), hyperpolarized bud

Received for publication December 14, 1990; accepted January 15, 1991.

Address reprint requests to John R. Pringle, Department of Biology, 4103 Natural Science Building, The University of Michigan, Ann Arbor, MI 48109-1048. 
TABLE 1. Saccharomyces cerevisiae Strains Used in This Study

\begin{tabular}{|c|c|c|}
\hline Strain & Relevant genotype & Source or reference \\
\hline $\mathrm{C} 276$ & $M A T a / M A T \alpha\left(\mathrm{Ts}^{+}\right.$, prototrophic diploid $)$ & Wilkinson and Pringle [1974] \\
\hline TD1 & $M A T \alpha$ ura3 his4 trp1 $\left(\mathrm{Ts}^{+}\right)$ & G. Fink \\
\hline CP1AB-1AA & MATa/MATa $\left(\mathrm{Ts}^{+}\right.$, prototrophic diploid) & Paquin and Adams [1982] \\
\hline CP1AB-1BB & $M A T \alpha / M A T \alpha\left(\mathrm{Ts}^{+}\right.$, prototrophic diploid) & Paquin and Adams [1982] \\
\hline LH104-HO1 & $M A T a / M A T \alpha c d c 3-1 / c d c 3-1$ & Adams and Pringle [1984] \\
\hline LH17012-HO1 & MATa/MAT $\alpha$ cdc10-1/cdc10-1 & Adams and Pringle [1984] \\
\hline JPT194-HO1 & $M A T a / M A T \alpha c d c 11-6 / c d c 11-6$ & Adams and Pringle [1984] \\
\hline JPTA1493-HO1 & MATa/MAT $\alpha$ cdc12-6/cdc12-6 & Adams and Pringle [1984] \\
\hline
\end{tabular}

growth, and a failure to complete cytokinesis [Hartwell, 1971; Adams, 1984; Adams and Pringle, 1984; Slater et al., 1985]. As the mutant cells continue to replicate DNA, undergo nuclear division, and form new buds, the mutants arrest as multinucleate cells with multiple, abnormally elongated buds.

Previous studies have shown that $C D C 3, C D C 10$, $C D C 11$, and $C D C 12$ encode a family of proteins that are $25-37 \%$ identical in amino acid sequence [Haarer et al., submitted]. In addition, antibodies specific for the $C D C 3, C D C 10$, and $C D C 12$ products (Cdc3p, Cdc10p, and Cdc12p) have been used to show by immunofluorescence that these proteins localize to the region occupied by the ring of $10 \mathrm{~nm}$ filaments and are probably constituents of this cytoskeletal element [Haarer and Pringle, 1987; Kim et al., 1991; Kim et al., manuscript in preparation]. Here we report the preparation of antibodies specific for the $C D C 11$ gene product (Cdc11p) and the use of these antibodies to localize this protein within cells in patterns very similar to those observed for Cdc3p, Cdc10p, and Cdc12p. We have also examined the timing of arrival of both Cdc11p and actin at presumptive budding sites, the timing of departure of these proteins from old budding sites after cytokinesis, and the localization of Cdc11p in cells undergoing morphogenetic changes during mating or in response to mating pheromone [Lipke et al., 1976; Schekman and Brawley, 1979; Tkacz and MacKay, 1979; Hašek et al., 1987; Trueheart et al., 1987].

\section{MATERIALS AND METHODS Reagents}

T4 DNA ligase, restriction endonucleases, and large (Klenow) fragment of DNA polymerase were obtained from Bethesda Research Laboratories (Gaithersburg, MD) or New England BioLabs (Beverly, MA). Calf intestine alkaline phosphatase was obtained from Boehringer Mannheim (Indianapolis, IN). Freund's complete and incomplete adjuvants, $3 \beta$-indoleacrylic acid, isopropyl $\beta$-D-thio-galactopyranoside (IPTG), DAPI, Coomassie Brilliant Blue R, Ponceau S, $\alpha$-factor, and nocodazole were obtained from Sigma (St. Louis, MO). FITC-conjugated and rhodamine-conjugated goat antirabbit-IgG (IgG fraction) and rhodamine-conjugated goat anti-rat-IgG (IgG fraction) were obtained from
United States Biochemical (Cleveland, OH). Rat antitubulin monoclonal antibody YOL1/34 was a gift from J. Kilmartin [Kilmartin et al., 1982]. Rhodamine-phalloidin was obtained from Molecular Probes (Eugene, OR) as a $3.3 \mu \mathrm{M}$ stock in methanol. "EIA grade" affinity-purified goat anti-rabbit-IgG $(\mathrm{H}+\mathrm{L})$ conjugated to horseradish peroxidase (HRP) was obtained from BioRad (Richmond, CA). Nitrocellulose paper BA 85 was obtained from Schleicher \& Schuell (Keene, NH).

\section{Plasmids, Strains, and Growth Conditions}

Plasmid pUR288 and $E$. coli strain BMH71-18 were handled essentially as described previously [Messing $e$ al., 1977; Rüther and Müller-Hill, 1983]. Plasmid pATH3 was provided by T.J. Koerner and A. Tzagoloff and was propagated in $E$. coli strain HB101 [Maniatis et $a l ., 1982$ ] as described previously [Haarer and Pringle, 1987]. Plasmid YEp24 was described previously [Botstein et al,, 1979]; YEp24(CDC11)S is a CDC11containing derivative [Lillie et al., submitted].

The $S$. cerevisiae strains used are listed in Table 1 . Except as noted, these strains were grown with rotary shaking in the rich, glucose-containing medium YM-P [Lillie and Pringle, 1980 ] at $\sim 23^{\circ} \mathrm{C}$. Strain TD1 was propagated in the appropriate selective media [Sherman et al., 1986] either without plasmid or after transformation with YEp24 or YEp24(CDC11)S. Temperature-sensitive cell-division-cycle mutant strains were grown to $\sim 10^{7}$ cells $/ \mathrm{ml}$ at $\sim 23^{\circ} \mathrm{C}$, then shifted to $36^{\circ} \mathrm{C}$ by dilution into fresh, pre-warmed medium.

\section{DNA Manipulations}

Standard procedures were used for recombinant DNA manipulations and $E$. coli transformations [Maniatis et al., 1982], yeast transformations [Hinnen et al., 1978], and the isolation of plasmid DNAs from $E$. coli [Birnboim and Doly, 1979; Holmes and Quigley, 1981].

\section{Isolation of Proteins, Gel Electrophoresis, and Protein Blotting}

Total $E$. coli proteins were isolated after growth under the appropriate inducing conditions as described previously [Haarer and Pringle, 1987]. To prepare total yeast proteins, cells were grown to $\sim 10^{7}$ cells $/ \mathrm{ml}$ in the appropriate medium. Approximately $10^{8}$ cells were then harvested by centrifugation at $\sim 23^{\circ} \mathrm{C}$ and then 
resuspended and processed further at $0-4^{\circ} \mathrm{C}$. After one wash in distilled water, the cells were suspended in 100 $\mu l$ lysis buffer with protease inhibitors, essentially as described previously [Haarer and Pringle, 1987], and ruptured by vortexing for several short periods with 0.5 $\mathrm{mm}$ glass beads. After the beads were removed by brief centrifugation, the lysate was either frozen at $-70^{\circ} \mathrm{C}$ until further use or diluted $1: 1$ with $2 \times$ loading buffer (58 mM Tris- $\mathrm{HCl}$ [pH 6.8], $735 \mathrm{mM} \beta$-mercaptoethanol, $10 \%$ glycerol, $2 \%$ sodium dodecyl sulfate [SDS], $0.01 \%$ bromophenol blue) and loaded directly onto a polyacrylamide gel. Total protein concentrations were normalized by the method of Bradford [1976].

SDS-polyacrylamide gels ( $8 \%, 0.7 \mathrm{~mm}$ thick) and the Laemmli [1970] buffer system were used for all protein electrophoresis. When desired, proteins were visualized by staining in $0.5 \%$ Coomassie Brilliant Blue R, $45 \%$ methanol, $10 \%$ acetic acid, and destaining in $20 \%$ methanol, $10 \%$ acetic acid. Alternatively, proteins were blotted to nitrocellulose [Burnette, 1981; Towbin et al., 1979] using a TE42 electroblotter (Hoefer, San Francisco, CA) with a current of $1 \mathrm{~A}$ for $2 \mathrm{~h}$. The blotted proteins were visualized by staining the nitrocellulose for $10 \mathrm{~min}$ in $0.2 \%$ Ponceau $\mathrm{S}$ in $0.3 \%$ trichloroacetic acid and destaining in PBS [Pringle et al., 1989]. Blots were then either used for affinity purification (see below) or stained with antibodies as described previously [Pringle et al., 1989].

\section{Preparation of Antigens and Antibodies}

Total proteins were isolated from $E$. coli strain BMH71-18 harboring fusion plasmid pUR288 (CDC11)12 (see Results) and from E. coli strain HB101 harboring fusion plasmid pATH3(CDC11)14 (see Results), and the $\beta$-galactosidase-Cdc11p and anthranilate synthase-Cdc11p fusion proteins were isolated by gel electrophoresis. For immunization, gel slices containing $50-100 \mu \mathrm{g}$ of fusion protein were homogenized, mixed at $\sim 2: 3$ with Freund's adjuvant (complete adjuvant for the initial injection; incomplete adjuvant for all subsequent injections) and injected subcutaneously into New Zealand White rabbits. Serum samples were prepared [Hurn and Chantler, 1980] from blood collected just before the first injection (preimmune sera) and 2-3 weeks after each booster injection (immune sera). Cdc11p-specific antibodies were affinity purified using nitrocellulose blots of the fusion proteins as described previously [Pringle $e t a l ., 1989$ ]. Except as noted, purification was done in two steps. Antibodies raised against the $\beta$-galactosidase-Cdc11p fusion were purified first on the anthranilate synthase-Cdc11p fusion and then on the $\beta$-galactosidase-Cdc1lp fusion; antibodies raised against the anthranilate synthaseCdc11p fusion were purified first on the $\beta$-galactosidase-Cdc11p fusion and then on the anthranilate synthase-Cdc11p fusion.

\section{Morphological Observations}

In most cases, cells were fixed by adding formaldehyde directly to the culture medium to a final concentration of $3.7 \%$ and incubating for $2-3 \mathrm{~h}$ at $\sim 23^{\circ} \mathrm{C}$ [Pringle et al., 1989]. With some antibody preparations, immunofluorescence was more successful when cells were initially fixed by adding glutaraldehyde directly to the culture medium to a final concentration of $0.025 \%$ and incubating for $3 \mathrm{~min}$, then washed in PBS, resuspended in $3.7 \%$ formaldehyde in PBS, and incubated for an additional $\sim 20 \mathrm{~min}$ at $\sim 23^{\circ} \mathrm{C}$ [Chen et al., 1985]. Indirect immunofluorescence, staining of actin with rhodamine-phalloidin, and staining of nuclear DNA with DAPI were performed as described previously [Pringle et al., 1989]. Proportions of budded and unbudded cells were determined by phase-contrast microscopy after sonication to disperse clumps [Pringle and Mor, 1975].

\section{Other Methods}

To depolymerize microtubules, cells were treated with nocodazole as described previously [Jacobs et al., 1988]. To arrest cell proliferation with $\alpha$-factor, strain CP1AB-1AA was grown to a density of $\sim 10^{7}$ cells $/ \mathrm{ml}$ and diluted into fresh medium to a concentration of 2 $\times 10^{6} \mathrm{cells} / \mathrm{ml}, \alpha$-Factor (from a stock solution of 1 $\mathrm{mg} / \mathrm{ml}$ in water) was then added to a final concentration of $5 \mu \mathrm{g} / \mathrm{ml}$, and incubation was continued for 160 min at $\sim 23^{\circ} \mathrm{C}$. For mating experiments, strains CP1AB-1AA and CP1AB-1BB were grown separately to $\sim 10^{7} \mathrm{cell} / \mathrm{s} / \mathrm{ml}$. Equal numbers of cells of each mating type were then mixed and collected onto $0.45 \mu \mathrm{m}$ Millipore (Bedford, MA) filters to yield $\sim 2.5 \times 10^{7}$ cells per $4.7 \mathrm{~cm}$ diameter filter. The filters were then placed on YPD plates [Sherman et al., 1986] and incubated for $1.5-2 \mathrm{~h}$ at $\sim 23^{\circ} \mathrm{C}$, after which the cells were collected by washing the filters with two 5 -ml changes of $0.9 \% \mathrm{NaCl}$ containing $3.7 \%$ formaldehyde.

\section{RESULTS \\ Construction of lacZ:CDC11 and trpE:CDC11 Gene Fusions}

Fusions of $C D C 11$ to the $E$. coli lac $Z$ and $\operatorname{trp} E$ genes were constructed as described in Figure 1. Analysis of the CDC11 DNA sequence [Haarer et al., submitted] predicted that these constructions would result in inframe fusions. As expected, induction of cells containing plasmid pATH3(CDC11)14 resulted in the synthesis of an $\sim 72 \mathrm{kD}$ fusion protein (Fig. 2A, lanes 1-3), and induction of cells containing plasmid pUR288(CDC11)12 resulted in the synthesis of an $\sim 150 \mathrm{kD}$ fusion protein (Fig. 2A, lanes 4-6).

\section{Production of Antibodies Specific for Cde11p}

The $\beta$-galactosidase-Cdc11p and anthranilate synthase-Cdc11p fusion proteins were used separately to elicit antibody production in rabbits (see Materials and 


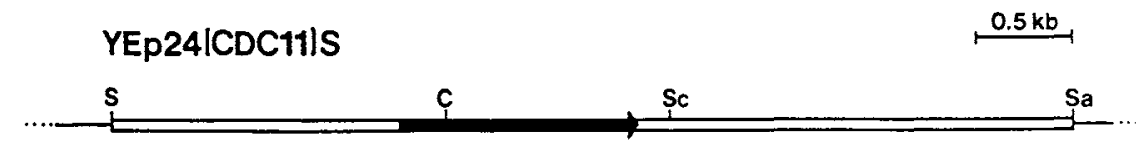

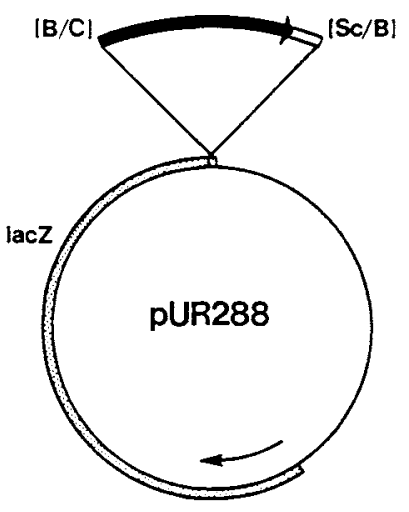

pUR288|CDC11/12
Fig. 1. Construction of lacZ:CDC11 and trpE:CDC11 gene fusions. The $1.165 \mathrm{~kb}$ ClaI-Scal fragment from YEp24 (CDC11)S was inserted into fusion vectors pUR288 and pATH3 to produce plasmids pUR288(CDC11)12 and pATH3(CDC11)14, respectively. In each case, the vector was linearized with $B a m H I$, followed by treatment with calf intestine alkaline phosphatase and the Klenow fragment of DNA polymerase to produce blunt ends, and then ligated to the gel-purified ClaI-ScaI fragment, which had itself been treated with Klenow fragment to produce two blunt ends. Fusions in the correct orientation

Methods). Immunoblotting showed that each of the resulting crude antisera was able to recognize both fusion proteins in crude extracts of $E$. coli strains harboring the appropriate fusion plasmids (Fig. $2 \mathrm{~B}$ and data not shown). Therefore, the sera appeared to contain antibodies specific for Cdc11p determinants, which are common to both fusion proteins.

Affinity-purified antibodies (see Materials and Methods) recognized an $\sim 55 \mathrm{kD}$ protein in blots of total proteins from $C D C 11$ (wild-type) cells containing no plasmid (Fig. 2C, lane 1) or plasmid YEp24 (Fig. 2C, lane 3 ). A stronger reaction at the same position was observed in extracts of the same strain harboring a high-copy-number plasmid containing the entire $C D C 11$ coding region (Fig. 2C, lane 2), indicating that the $\sim 55 \mathrm{kD}$ protein is the authentic $C D C 11$ gene product. The estimated molecular weight of $\sim 55 \mathrm{kD}$ is somewhat greater than the $47.7 \mathrm{kD}$ predicted from DNA sequence analysis [Haarer et al., submitted]; the reason for this discrepancy is not yet understood. In blots of the overproducing strain, two additional polypeptides of $\sim 30$ and $\sim 40 \mathrm{kD}$ were detectable (Fig. $2 \mathrm{C}$, lane 2). As these polypeptides were not visible in extracts of control strains (Fig. 2C, lanes 1,3), they probably represent breakdown products of Cdc11p.

When the affinity-purified antibodies were used at were identified by restriction site analysis (not shown). Large solid arrows represent the $C D C 11$ coding region, as inferred from DNA sequence analysis [Haarer et al., submitted]; open boxes represent adjacent yeast DNA; stippled boxes represent the $l a c Z$ and $\operatorname{trp} E$ coding regions; and thin lines represent either pBR322-derived or $E$. coli DNA. Small arrows indicate the directions of transcription for the two fusion genes. Restriction sites are indicated: B, BamHI; C, ClaI; S, SalI; Sa, Sau3A; Sc, ScaI.

high concentrations on blots of total proteins from wildtype cells, they reacted weakly with four other proteins in addition to Cdc11p (Fig. 2D, lanes 1-4). Three of these proteins (those of $\sim 66 \mathrm{kD}, \sim 43 \mathrm{kD}$, and $\sim 37$ $\mathrm{kD})$ comigrated approximately with $\mathrm{Cdc} 3 \mathrm{p}, \mathrm{Cdc1} 2 \mathrm{p}$, and Cdc10p, respectively [Haarer and Pringle, 1987; data not shown]; such possible cross-reactivity would not be surprising given the sequence similarities between these proteins and Cdc11p [Haarer et al., submitted].

\section{Immunofluorescence Localization of Cdc11p in Wild-type and Mutant Cells}

Staining of wild-type cells with the affinity-purified antibodies revealed a localization for Cdc11p (Fig. $3 \mathrm{~A}, \mathrm{G})$ similar to that observed previously for Cdc3p, Cdc10p, and Cdc12p [Haarer and Pringle, 1987; Kim et al., 1991; Kim et al., manuscript in preparation]. In cells with buds of various sizes, the staining revealed a double-band structure surrounding the mother-bud neck (Fig. 3A, cells 1-4). This staining pattern is consistent with the hypothesis that Cdc11p is a constituent of the ring of $10 \mathrm{~nm}$ filaments that lies directly subjacent to the plasma membrane in the neck region [Byers and Goetsch, 1976a; Byers, 1981; Haarer and Pringle, 1987; see also below]. Evidence that the stain- 
A

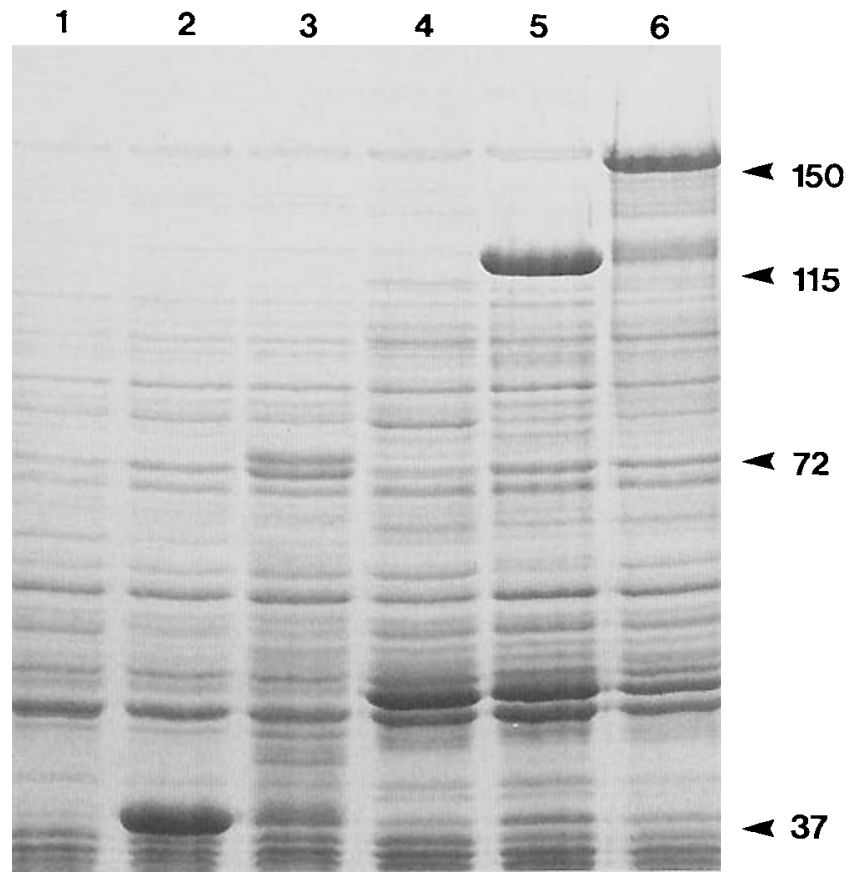

Fig. 2. A: Identification of anthranilate synthase-Cdc11p and $\beta$ galactosidase-Cdc11p fusion proteins by SDS-polyacrylamide gel electrophoresis. Lanes 1-3: Total proteins prepared from $E$. coli strain HB101 containing (lane 1) no plasmid; (lane 2) plasmid pATH3; or (lane 3) plasmid pATH3(CDC11)14. Lanes 4-6: Total proteins prepared from $E$. coli strain BMH71-18 containing (lane 4) no plasmid; (lane 5) plasmid pUR288; or (lane 6) plasmid pUR288(CDC11)12. In all cases, strains were propagated under inducing conditions [Haarer and Pringle, 1987]. The approximate sizes of the truncated anthranilate synthase and $\beta$-galactosidase proteins encoded by the vectors and of the fusion proteins are given in kilodaltons. B: Recognition of $\beta$-galactosidase-Cde11p and anthranilate synthase-Cdc11p fusion proteins on blots by antisera raised against the fusion proteins. Total proteins prepared from (lane 1) $E$. coli strain BMH71-18 containing plasmid pUR288(CDC11)12 or (lane 2) E. coli strain HB101 containing plasmid pATH3(CDC11)14 were electrophoresed, blotted to nitrocellulose, and reacted with antibodies. The primary antibodies used were 1:200 dilutions of crude sera obtained from rabbits immunized with the (lane 1) anthranilate synthase-Cdc11p or (lane 2) $\beta$-galactosidase-Cdc11p fusion proteins. The secondary antibody used was a 1 : 250 dilution of HRP-conjugated goat anti-rabbit-IgG. The approximate sizes of the fusion proteins are given in kilodaltons. C: Identification of Cdc11p using affinity-purified antibodies. Total

ing pattern observed reflects the localization of Cdc11p, and not that of one of the cross-reacting species (Fig. 2D), was obtained by repeating the staining using the primary antibodies at various dilutions. Staining of the neck region was weakly visible even when the antibodies were used at a 1:250 dilution (data not shown); when the same antibody preparation was used at this concentration to stain Cdc11p on blots, staining was still strong, whereas no staining of cross-reacting species was detectable (Fig. 2D). In dividing cells, the bands of fluorescence appeared as separate structures

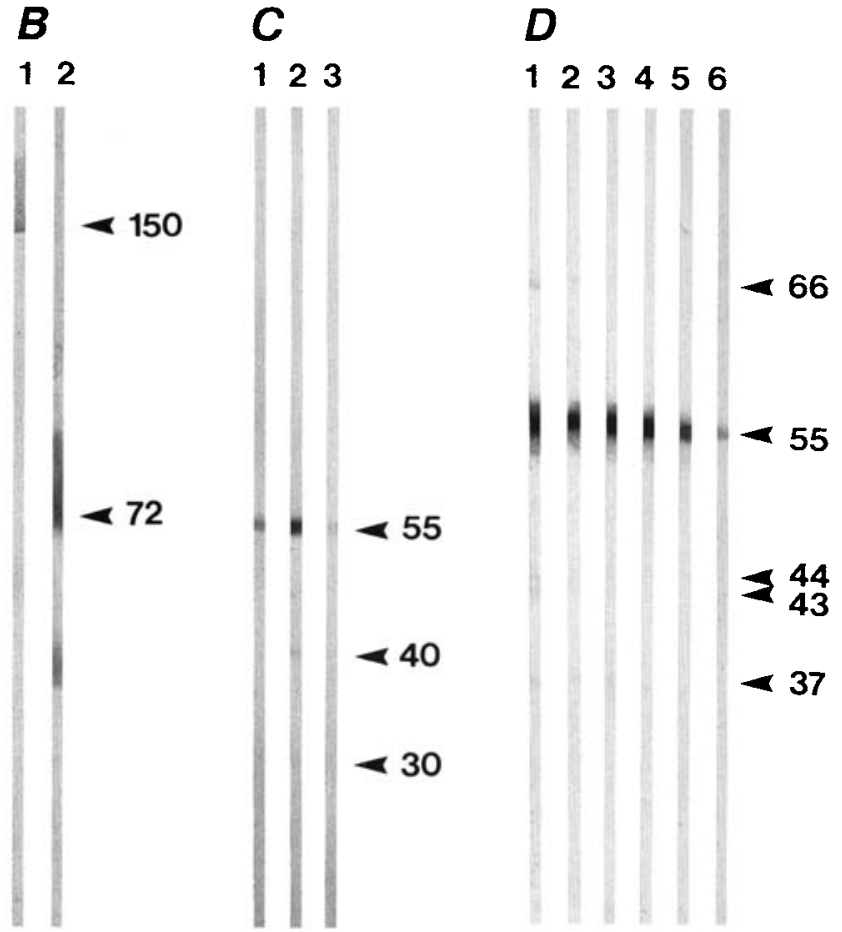

cellular proteins prepared from strain TD1 containing (lane 1) no plasmid, (lane 2) plasmid YEp24(CDC11)S, or (lane 3) plasmid YEp24 were electrophoresed, blotted to nitrocellulose, and reacted with a 1:200 dilution of affinity-purified antibodies raised against the anthranilate synthase-Cdc11p fusion protein. (The antibodies used were those obtained after the first boost of rabbit 4 , Table 2 . For this experiment, the affinity purification used only the first step of the two-step procedure described in Materials and Methods.) The secondary antibody used was a 1:250 dilution of HRP-conjugated goat antirabbit-IgG. The position of the putative wild-type $C D C 11$ gene product at $-55 \mathrm{kD}$ is indicated. The lower two arrowheads indicate the positions of a pair of additional bands visible only in lane 2 (see text). D: Cross-reactivity of the affinity-purified Cdc11p-specific antibodies with other yeast proteins. Total cellular proteins isolated from strain C276 were electrophoresed, blotted to nitrocellulose, and reacted with (lane 1) tenfold, (lane 2) 25-fold, (lane 3) 50-fold, (lane 4) 100-fold, (lane 5) 500-fold, and (lane 6) 2,500-fold serial dilutions of affinitypurified antibodies raised against the $\beta$-galactosidase-Cdc $11 p$ fusion protein. (The antibodies used were those obtained after the fifth boost of rabbit 1, Table 2.) The secondary antibody used was a 1:250 dilution of HRP-conjugated goat anti-rabbit-IgG. The approximate sizes of $\mathrm{Cdc} 11 \mathrm{p}$ and of the weakly cross-reacting proteins are given in kilodaltons.

of enlarged diameter and diminished staining intensity (Fig. 3A, cell 5).

Surprisingly, most preparations of affinity-purified Cdc11p-specific antibodies also appeared to stain both the nuclear and cytoplasmic microtubules. With three of the four rabbits immunized, the putative microtubule staining was undetectable with the preimmune sera but was strong with the antibodies obtained after one boost with fusion protein (Fig. 3B,C; Table 2, rabbits 1,2 , and 4). With the fourth rabbit, the putative microtubule staining was weakly detectable with the 

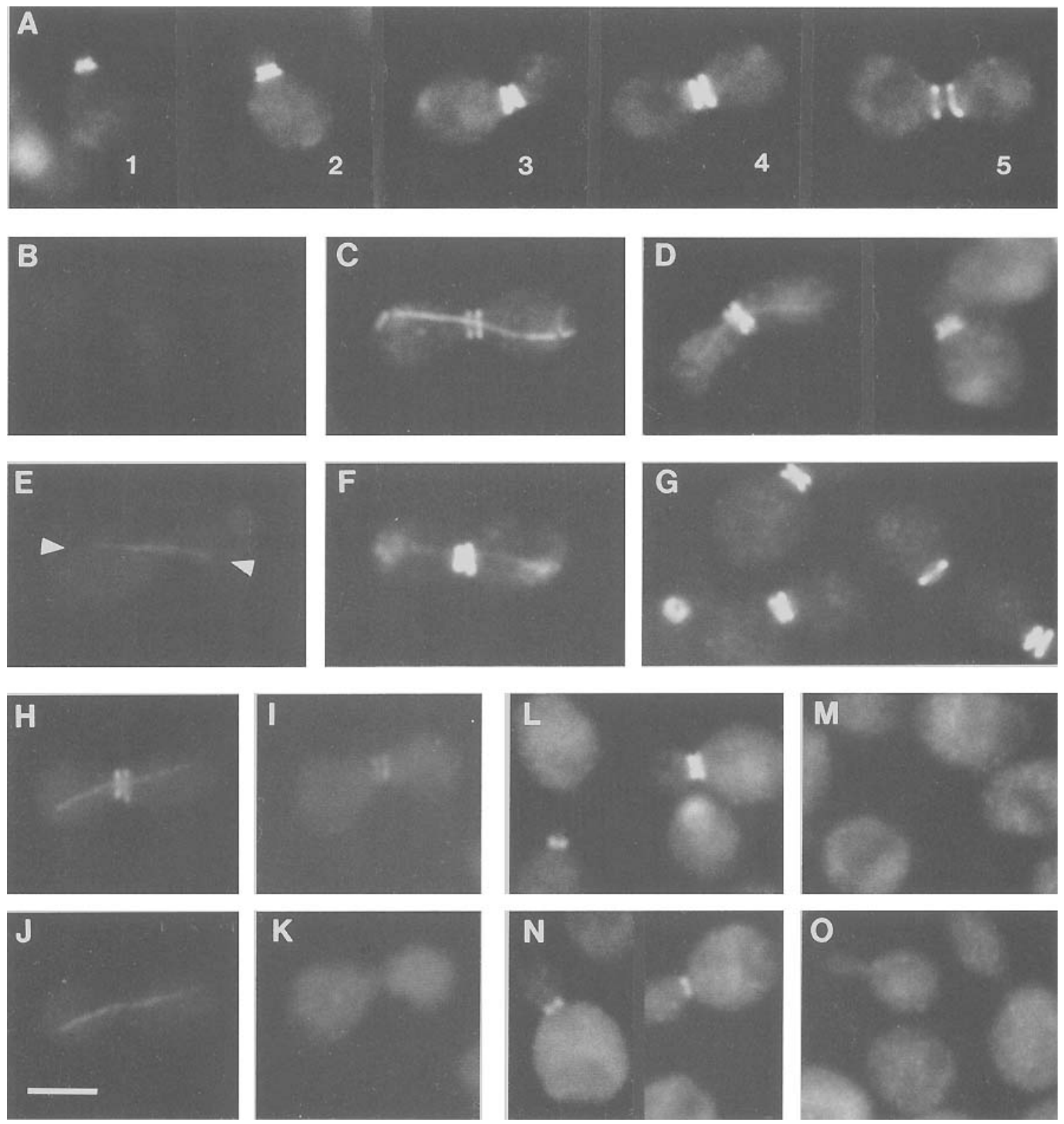

Fig. 3. Immunofluorescence localization of Cdc11p in wild-type (strain C276) and mutant cells. A: Wild-type cells stained with a 1:5 dilution of antibodies affinity-purified from serum obtained after a fifth boost with $\beta$-galactosidase-Cdc11p fusion protein (rabbit 1 of Table 2); the secondary antibody was rhodamine-conjugated goat antirabbit-IgG used at a 1:400 dilution. Individual cells are labeled for reference in the text. B-G: Wild-type cells stained with preimmune sera $(B, E)$ or with immune sera obtained after the first (C,F) or fifth (D,G) boost with the $\beta$-galactosidase-Cdc11p (B-D; rabbit 1 of Table 2$)$ or anthranilate synthase-Cdc1lp (E-G; rabbit 3 of Table 2) fusion protein. Preimmune sera were prepared for immunofluorescence using a procedure parallel to that used for affinity purification of Cdc11p-specific antibodies from immune sera and were then used without dilution; affinity-purified immune sera were used at a 1:1 dilution. The secondary antibody was rhodamine-conjugated goat anti-rabbit-IgG used at a 1:400 dilution. The arrowheads in panel $\mathbf{E}$

indicate the stained microtubules. H-K: Wild-type cells doublestained with antibodies raised against the $\beta$-galactosidase-Cdc11p fusion protein $(\mathrm{H}, \mathbf{I})$ and antitubulin antibodies $(\mathrm{J}, \mathrm{K})$ either prior to nocodazole treatment $(\mathrm{H}, \mathrm{J})$ or after treatment with nocodazole for $1 \mathrm{~h}$ $(\mathrm{I}, \mathrm{K})$. The Cdc11p-specific antibodies were affinity purified from serum obtained after the first boost of rabbit 1 (Table 2) and used at a 1:1 dilution. The rat monoclonal antitubulin antibody was used at a 1:100 dilution. The secondary antibodies were FITC-conjugated goat anti-rabbit-IgG used at 1:100 dilution and rhodamine-conjugated goat anti-rat-IgG used at 1:200 dilution. L-O: Mutant cells stained with the same primary and secondary antibody preparations and concentrations as used in panel A. L,N,O: JPT194-HO1 (cdc11) cells grown at $\sim 23^{\circ} \mathrm{C}(\mathrm{L})$ or at $36^{\circ} \mathrm{C}$ for $0.5 \mathrm{~h}(\mathrm{~N})$ or $2.5 \mathrm{~h}(\mathrm{O})$. M: LH17012-HO1 (cdc10) cells grown at $36^{\circ} \mathrm{C}$ for $0.5 \mathrm{~h}$. The scale for all panels is shown by the bar in panel $J$, representing $5 \mu \mathrm{m}$. 
TABLE 2. Intensity of Staining of Microtubules and Neck Regions Using Preimmune Sera and Affinity-purified Immune Sera*

\begin{tabular}{l} 
Type of serum \\
\cline { 2 - 4 } \\
Tyme
\end{tabular}

preimmune serum and was stronger after one boost with fusion protein (Fig.3E, F; Table 2, rabbit 3). With at least some of the sera obtained after one boost, the staining of microtubules was particularly strong (relative to that of the neck regions) when the standard formaldehyde fixation was used (see Materials and Methods). With all four rabbits, the antibodies obtained after five boosts with fusion protein displayed strong staining of the neck regions while the putative microtubule staining was reduced or undetectable (Fig. $3 D, G$; Table 2). Confirmation that the staining really was of microtubules was obtained by double labeling with Cdc11p-specific and antitubulin antibodies both normal cells (Fig. $3 \mathrm{H}, \mathrm{J}$ ) and cells whose microtubules had been depolymerized with nocodazole (Fig. 3I,K); staining of nuclear DNA with DAPI (data not shown) confirmed that both nuclear and cytoplasmic microtubules were stained in the normal cells. As the microtubule staining was more conspicuous at relatively high concentrations of the Cdc11p-specific antibodies (compare Fig. 3D to Fig. 3A), it is possible that the microtubule staining reflects the localization of one of the cross-reacting proteins (Fig. 2D). Other possibilities are considered in the Discussion.

Mutants defective in $C D C 3, C D C 10, C D C 11$, or CDC12 are unable to form or (for some alleles of $C D C 10$ and $C D C 12$ ) maintain rings of $10 \mathrm{~nm}$ filaments after a shift to restrictive temperature [Byers and Goetsch, 1976b; Adams, 1984]. To investigate further the association of Cdc11p with the filaments, immunofluorescence staining was performed on representative mutant strains (see Table 1). At permissive temperature, all four mutants showed seemingly normal local- ization of Cdc11p, although the background fluorescence seemed higher than normal in all cases and the intensity of the ring staining appeared somewhat diminished in the $c d c 3$ and $c d c 11$ cells (Fig. 3L and data not shown). After $0.5 \mathrm{~h}$ or longer at restrictive temperature, there was no detectable localized staining of Cdc11p in either cdc10 or cdc12 cells (Fig. 3M and data not shown). Under the same conditions, Cdc11p was still localized to the neck in $c d c 3$ and $c d c 11$ cells, but the staining was diminished in intensity as compared to that found at permissive temperature; moreover, there was a slight change in the apparent localization. Instead of a double-band structure (cf. Fig. 3A, cells 1-4), there was a single band of reduced diameter lying in the center of the neck (Fig. $3 \mathrm{~N}$ ). After $2.5 \mathrm{~h}$ at restrictive temperature (at which time only buds formed since the temperature shift should be present), no localization of Cdc11p was detected in cdc3 or cdc11 cells (Fig. 30 and data not shown). These patterns of localization for Cdc11p correspond closely to the behavior of the $10 \mathrm{~nm}$ filaments in these mutant strains, as judged by electron microscopy [Byers and Goetsch, 1976b; Adams, 1984], and thus support the hypothesis that Cdc11p is a constituent of these filaments. When any of the four mutant strains was shifted to restrictive temperature for $2 \mathrm{~h}$ and then stained with affinity-purified antibodies obtained after the first boost of rabbit 1 (Table 2), staining of microtubules was still detectable, although staining of the neck regions was absent (data not shown).

It seemed possible that comparison of the behavior of $\mathrm{Cdc} 3 \mathrm{p}, \mathrm{Cdc10p}, \mathrm{Cdc} 11 \mathrm{p}$, and $\mathrm{Cdc} 12 \mathrm{p}$ in the various mutants would provide clues to the structural arrange- 

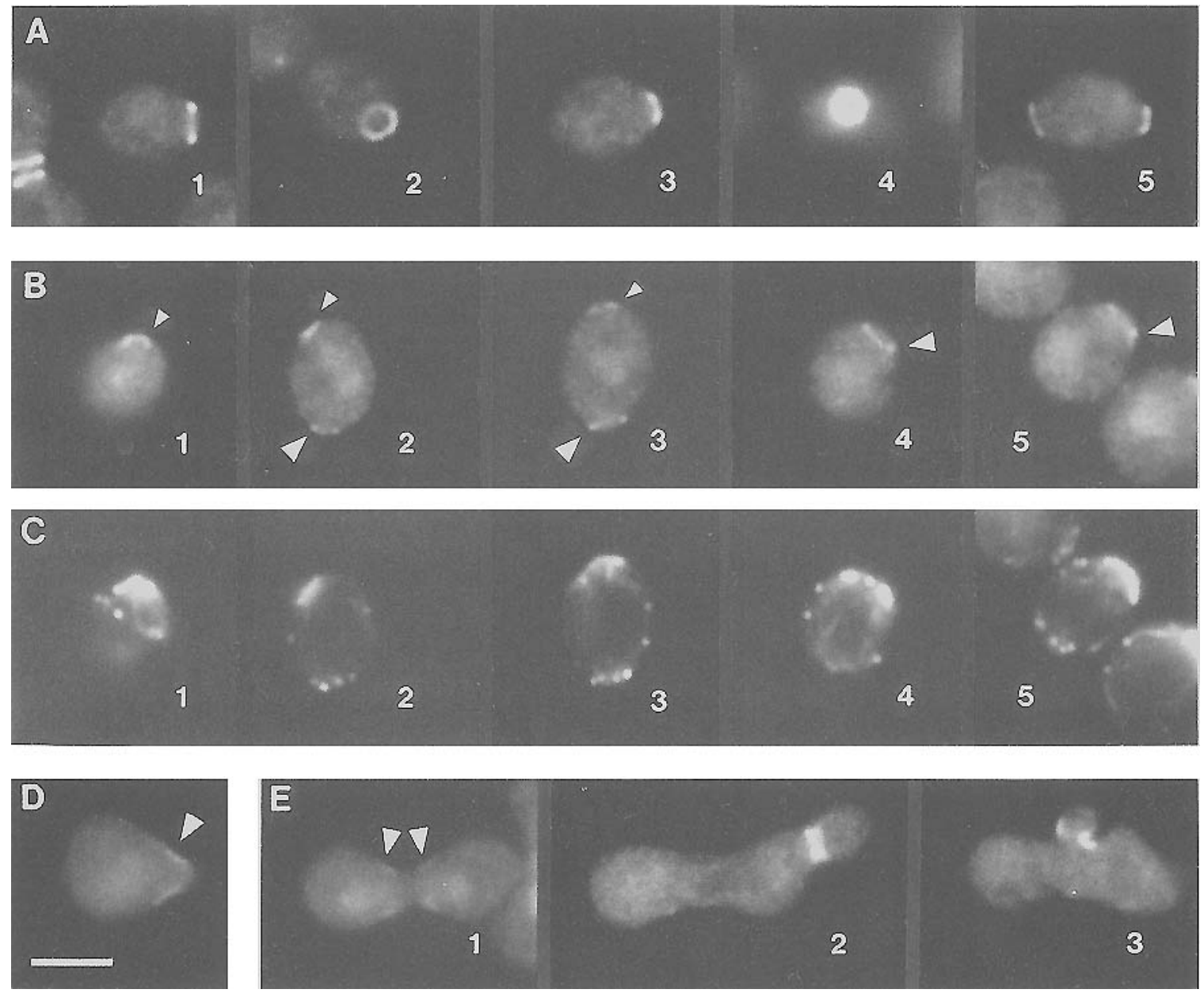

Fig. 4. Localization of Cdc11p and of actin in unbudded wild-type cells and localization of Cdc11p in shmoos and zygotes. A: Unbudded wild-type cells (strain C276) stained with the same primary and secondary antibody preparations and concentrations as used in Figure 3A. Individual cells are labeled for reference in the text. B,C: Unbudded strain C276 cells double-stained with Cdc11p-specific antibodies (B) and rhodamine-phalloidin (C). The primary antibody used was a 1:4 dilution of a separate affinity-purified preparation from the same serum as that used in Figure 3A; the secondary antibody was FITCconjugated goat anti-rabbit-IgG used at a 1:100 dilution. Rhodaminephalloidin was used at a 1:10 dilution of the stock solution supplied by the manufacturer (see Materials and Methods). Individual cells are

ments or order of assembly of the proteins in the neck filaments. However, staining of the other three antigens paralleled that of Cdc11p (see above) both in $c d c 10$ or $c d c 12$ strains and in $c d c 3$ or $c d c 11$ strains [Haarer and Pringle, 1987; Kim et al., 1991; Kim et al., manuscript in preparation; data not shown].

\section{Timing of Events at the Budding Site}

Electron microscopy has suggested that the ring of $10 \mathrm{~nm}$ filaments appears approximately coincident with bud emergence and disappears just prior to cytokinesis [Byers and Goetsch, 1976a; Byers, 1981]. We labeled for reference in the text. Small arrowheads indicate "new" Cdc11p rings; large arrowheads indicate "old" Cdc11p rings. D: Shmoo (strain CP1AB-1AA) observed after treatment with $\alpha$-factor for $160 \mathrm{~min}$ and staining with a 1:5 dilution of the same primary antibody preparation as used in panel $\mathrm{B}$; the secondary antibody was as used in Figure $3 \mathrm{~A}$. The arrowhead indicates the localization of staining in the shmoo tip. E: Zygotes formed by mating strains CP1AB-1AA and CP1AB-1BB and stained either as in panel D (zygote 1) or as in panel A (zygotes 2 and 3). Individual zygotes are labeled for reference in the text. The arrowheads indicate localized staining in the conjugation bridge. The scale for all panels is shown by the bar in panel $\mathrm{D}$, representing $5 \mu \mathrm{m}$.

asked if the localization of Cdc11p to the budding site corresponded to this apparent timing of filament assembly and disassembly by examining the immunofluorescence patterns of the unbudded cells from an exponentially growing population of wild-type cells. Remarkably, nearly all such cells displayed rings of Cdc11p. These rings were of two types: brightly stained rings of smaller diameter (Fig. 4A, cells $3-5$ ) and less brightly stained rings of larger diameter (Fig. 4A, cells 1,2 , and 5). In a sample of 657 unbudded cells, $6.5 \%$ had one small ring only, $58 \%$ had one large ring only, $35 \%$ had one ring of each type (typically at opposite 
poles; see Fig. 4A, cell 5), and just $0.2 \%$ had no visible ring. The similarities of the small rings to those found on cells with small buds (cf. Fig. 3A, cell 1) and of the large rings to those found on dividing mother and daughter cells (cf. Fig. 3A, cell 5) suggest that the small rings are formed in anticipation of subsequent bud emergence and that the large rings are those remaining from the previous cell cycles. This interpretation is supported by the presence of both types of rings on some cells, by the coincidence of both small and large rings with concentrations of actin (see below), and by related observations (including studies of synchronized cultures) made using Cdc3p-specific and Cdc10p-specific antibodies [Kim et al., 1991; Kim et al., manuscript in preparation]. In addition, when $c d c 3$ and cdc11 mutant strains were shifted to restrictive temperature for $0.5 \mathrm{~h}$ and then stained with affinity-purified antibodies, no localization of Cdc11p was detected in unbudded cells, consistent with the inability of these mutants to form new rings of $10 \mathrm{~nm}$ filaments at restrictive temperature [Byers and Goetsch, 1976b; Adams, 1984] (cf. also Fig. 3N and associated text).

If our interpretation of the two types of rings is correct, we can calculate the approximate timing of appearance and disappearance of a detectable ring of Cdc11p. For the exponentially growing population sampled, the generation time was $119 \mathrm{~min}$, and 29\% of the cells were unbudded (as determined by phase-contrast microscopy); thus, the mean unbudded period would be $\sim 27 \mathrm{~min}$ [Hartwell and Unger, 1977]. By similar calculation, the ring of Cdc11p would appear $\sim 13 \mathrm{~min}$ before bud emergence and linger $\sim 24 \mathrm{~min}$ after cell division, on average. In some cells, the "old" ring of Cdc11p persisted throughout the entire unbudded phase and was still evident early in the next budding cycle (data not shown).

As actin also becomes concentrated at the budding site and appears to play a critical role in bud emergence and bud growth (see Introduction), it was of interest to determine the relative timing of the arrival of actin and of Cdc11p at presumptive budding sites. To do this, exponentially growing wild-type cells were double-stained with Cdc11p-specific antibodies and with rhodamine-phalloidin. In a sample of 394 unbudded cells, 175 of 175 "new" Cdc11p rings observed had associated clusters of actin (Fig. 4B,C, cells 1-3, small arrowheads), as did 346 of 362 "old" Cdc11p rings (Fig. $4 \mathrm{~B}, \mathrm{C}$, cells $2-5$, large arrowheads). In addition, one cell with a "new" Cdc11p ring and associated actin cluster at one pole displayed a second actin cluster without an associated ring of Cdc11p at the opposite pole, whereas 18 cells with an "old" Cdc11p ring and associated actin cluster at one pole displayed a second actin cluster without an associated ring of Cdc11p at the opposite pole (Fig. 4B,C, cell 5). Only one cell in this sample failed to show any ring of Cdc11p; it possessed an actin cluster at one pole. From these results, we infer that the actin concentration at a previous budding site usu- ally (but not always) becomes undetectable a short time before the ring of Cdc11p becomes undetectable, whereas the actin cluster at a future budding site normally forms coincident with or shortly before the appearance of a detectable ring of Cdc11p at that site.

\section{Localization of Cdc11p in Shmoos and Zygotes}

Cells engaged in mating or responding to mating pheromone undergo localized changes in cell-wall organization (including chitin deposition) that appear related to those occurring in budding cells. Thus, it was of interest to ask if Cdc11p also localized to the sites of cell-wall reorganization in shmoos and zygotes. Immunofluorescence staining of shmoos typically revealed a faint, but distinct, band of staining around the growing tip (Fig. 4D), corresponding approximately to the region of chitin deposition in such cells (unpublished observations). In zygotes observed soon after fusion, Cdc11p could occasionally be detected faintly in the conjugation bridge (Fig. $4 \mathrm{E}$, zygote 1 ). The staining pattern was variable, sometimes appearing as two weakly staining bands on either side of the point of contact, again corresponding approximately to the regions of chitin deposition (unpublished observations). Zygotes that had initiated budding possessed the typical pattern of staining seen in budding cells (Fig. $4 \mathrm{E}$, zygotes 2 and 3); staining of the conjugation bridge was rarely, if ever, observed in zygotes at this stage.

\section{DISCUSSION}

The S. cerevisiae CDC3, CDC10, CDC11, and CDC12 genes and their products are involved in the morphogenetic events of the cell cycle: mutation of any of these genes produces pleiotropic morphogenetic abnormalities including a failure to form the ring of $10 \mathrm{~nm}$ filaments that normally lies immediately subjacent to the plasma membrane in the mother-bud neck (see Introduction). These observations suggested that the $C D C 3$, $C D C 10, C D C 11$, and $C D C 12$ products might be constituents of the ring of $10 \mathrm{~nm}$ filaments and, thus, that the other morphological abnormalities observed in the mutants might be consequences of the failure to form these filaments. Evidence supporting this hypothesis has been obtained previously using antibodies specific for Cdc3p, Cdc10p, and Cdc12p: in immunofluorescence experiments on wild-type and mutant cells, all three proteins localize as expected for constituents of the $10 \mathrm{~nm}$ filaments [Haarer and Pringle, 1987; Kim et al., 1991; Kim et al., manuscript in preparation]. Given the similar phenotypes of the $c d c 3, c d c 10, c d c 11$, and cdc12 mutants, the extensive homologies in amino acid sequence among the predicted $C D C 3, C D C 10, C D C 11$, and $C D C 12$ products [Haarer et al., submitted], and the extensive genetic evidence for interactions among these genes and/or their products [Pringle et al., 1986; Lillie et al., submitted], we anticipated that Cdc11p would display a similar localization. 
To investigate this issue, we used $\beta$-galactosidaseCdc11p and anthranilate synthase-Cdc11p fusion proteins to elicit and affinity purify antibodies that could recognize Cdc11p in blots of yeast proteins. These antibodies appeared to be highly but not completely specific for Cdc11p: when the highest-titer antibodies (those obtained after five boosts with fusion protein) were used at high concentrations to stain blots of yeast proteins, four faint bands were observed in addition to the very strong band of Cdc11p. Three of these bands had mobilities corresponding to those of Cdc3p, Cdc10p, and Cdc12p and might in fact be those proteins; such cross reaction would not be surprising given the extensive sequence similarities among these proteins [Haarer et al., submitted]. As the reaction with Cdc11p appears to be $\geq 1,000$-fold stronger than the reaction with any of the other species, it seems likely that the immunofluorescence patterns observed reflect the true localization of Cdc11p, and not that of any of the cross-reacting species. However, we cannot exclude the possibility that a protein recognized weakly (or not at all) on blots is recognized more strongly when presented in fixed cells, and thus contributes significantly to the immunofluorescence patterns observed.

That such concerns may not be trivial is suggested by the perplexing observation that most of our preparations of ostensibly Cdc11p-specific antibodies stained not only the region of the $10 \mathrm{~nm}$ filaments but also both the cytoplasmic and nuclear microtubules. This staining was particularly prominent with the sera obtained after one boost with the fusion proteins, where the microtubule staining was in some cases brighter than the staining of the $10 \mathrm{~nm}$ filaments, particularly when the standard formaldehyde fixation protocol was used (see Materials and Methods). There appear to be three possible explanations for these observations: 1 ) production of antibodies specific for tubulin or some other microtubule-associated protein might have been nonspecifically stimulated by the immunization regimen; 2 ) tubulin or some other microtubule-associated protein might share one or more epitopes with Cdc11p; and 3) a fraction of the Cdc11p might actually be associated with the microtubules. Possibility 1 is supported by the observations that microtubule-recognizing antibodies were present in the preimmune serum from at least one rabbit, that microtubule-recognizing antibodies have been observed also after immunizing with the totally unrelated protein Dedlp/Spp81p [B. Rahe and J. Pringle, unpublished observations; see also Jamieson et al., 1991], and that immunization with Cdc12p fusion proteins also resulted in an apparently gratuitous induction of unrelated antibodies (recognizing in this case some component of the cell wall) [Haarer and Pringle, 1987]. However, possibility 1 appears difficult to reconcile with the observations that microtubule staining was visible even after two-step affinity purification and that the titer of microtubule-recognizing antibodies was boosted dramatically in all four rabbits during the early stages of immunization. These latter observations appear most consistent with possibility 2 or 3 . However, possibility 3 appears difficult to reconcile with the observations that temperature shift of a cdc11 mutant could eliminate staining of the neck filaments without obviously affecting the staining of the microtubules and that the apparent titer of microtubule-recognizing antibodies declined precipitously (to undetectable levels with two rabbits) upon repeated booster injections with the Cdc11p fusion proteins. Thus, the balance of the evidence appears to favor possibility 2 . However, it must be noted that this hypothesis itself is somewhat difficult to reconcile with the failure to observe more prominent bands of cross-reacting proteins on blots (Fig. 2C,D; results similar to those of Fig. 2C were also obtained with the first-boost serum from rabbit 1 , with which the microtubule staining was even stronger [Table 2]). Thus, we cannot exclude the interesting possibility that a fraction of the Cdc11p is associated with the microtubules.

With these caveats only noted, the intracellular localization of Cdc11p in both wild-type and mutant cells appears to be essentially the same as that of Cdc3p, Cdc10p, and Cdc12p. Moreover, this localization is consistent with that expected for a constituent of the 10 $\mathrm{nm}$ filaments in the mother-bud neck, except for one apparent discrepancy. Elcctron microscopy has suggested that the ring of $10 \mathrm{~nm}$ filaments assembles coincident with bud emergence and disassembles just prior to cytokinesis [Byers and Goetsch, 1976a; Byers, 1981]. In contrast, the immunofluorescence observations indicate that Cdc $11 \mathrm{p}$ forms a well organized ring at the presumptive budding site well before bud emergence and lingers at that site well after cytokinesis (indeed, often throughout the entire subsequent unbudded phase). Similar observations have been made for Cdc3p and Cdc10p [Kim et al., 1991; Kim et al., manuscript in preparation]. The apparent discrepancy may well have a trivial explanation in the undoubted difficulty of visualizing the $10 \mathrm{~nm}$ filaments by electron microscopy; this problem would be especially severe in examining unbudded cells [B. Byers, personal communication]. However, the interesting possibility remains that the filament-associated proteins can assemble at the budding site, and perhaps function, without assembling into the higher-order structure visualized in the electron microscope as $10 \mathrm{~nm}$ filaments.

The question of the relationship between the formation of filaments and the function of these proteins is also raised by the observations on shmoos and zygotes. The diffuse and rather faint immunofluorescence staining observed with these cells using Cdc11p-specific (this study) or Cdc3p-, Cdc10p-, or Cdc12p-specific [Kim et al., 1991; Kim et al., manuscript in preparation] antibodies is not suggestive of a ring of filaments such as that found in budding cells. Moreover, to our knowledge, $10 \mathrm{~nm}$ filaments have not been observed in shmoos or zygotes by electron microscopy. However, it 
must be noted that there is also no good evidence that the proteins actually function in such cells. Although the localization of the proteins to regions of active cellwall reorganization is suggestive, the staining of zygotes was not consistent, and shifts of $c d c 3, c d c 10$, and cdc12 mutants to restrictive temperature produced no immediate loss of mating ability [Reid and Hartwell, 1977].

In any case, it should be stressed that the most economical interpretation of the available data is that $\mathrm{Cdc} 3 \mathrm{p}, \mathrm{Cdc10p}, \mathrm{Cdc11p}$, and Cdc12p are the primary constituents of the $10 \mathrm{~nm}$ filaments. If so, then the novelty of these proteins' sequences [Haarer et al., submitted] suggests that these filaments may represent a novel type of eukaryotic cytoskeletal element. We are presently investigating whether similar proteins and filaments exist in other kinds of cells. To date, we have identified several members of this protein family in the evolutionarily distant yeast Schizosaccharomyces pombe [T. Pugh, H.B. Kim, A. Healy, P. Fantes, and J.R. Pringle, manuscript in preparation]; it is not yet clear whether these proteins assemble into filaments like those seen in $S$. cerevisiae. Preliminary evidence suggests that similar proteins may exist in Drosophila as well (J. Fares and J.R. Pringle, unpublished results).

Meanwhile, there remain many questions about the function of these proteins and filaments in $S$. cerevisiae. One puzzle is why the assembly and function of the filaments require all four of the known filamentassociated proteins. We had hoped that comparing the localizations of Cdc3p, Cdc10p, Cdc11p, and Cdc12p in the various mutants at various times after shift to restrictive temperature would reveal differences that might provide clues to the structural arrangements or order of assembly of the proteins. To date, however, no convincing differences have been observed.

Another set of puzzles concerns the mechanisms by which the organization of the filament-associated proteins at presumptive budding sites is triggered at the appropriate time and at a single, nonrandom [Chant et al., submitted] location. This organization appears to be essentially coincident with that of the actin cytoskeleton at the same sites. As actin localization to these sites may occur slightly earlier than that of the filament-associated proteins (see Results), it is conceivable that the actin cytoskeleton helps direct the filament-associated proteins to the proper site. However, it seems more likely that these are independent events that are both dependent on some common upstream signal(s). It is interesting that the organization of these proteins at presumptive budding sites seems to precede the duplication of the spindle-pole body, as Byers and Goetsch [1975] observed no unbudded cells with duplicated spindle-pole bodies by electron microscopy. Thus, the cytoskeletal organization at the presumptive budding site must be among the earliest events occurring after Cdc28p protein kinase activity is triggered during the cell-cycle-controlling Start event [Pringle and Hartwell, 1981; Wittenberg et al., 1990].

\section{ACKNOWLEDGMENTS}

We thank Breck Byers, Hyong Kim, Brian Haarer, Charlie Jacobs, and Sue Lillie for helpful discussions and Sue Lillie for providing plasmid YEp24(CDC11)S. This work was supported by NIH grant GM31006.

\section{REFERENCES}

Adams AEM (1984): Ph.D. Thesis, The University of Michigan, Ann Arbor, Michigan.

Adams AEM, Pringle JR (1984): Relationship of actin and tubulin distribution to bud growth in wild-type and morphogenetic-mutant Saccharomyces cerevisiae. J Cell Biol 98:934-945.

Adams AEM, Botstein D, Drubin DG (1989): A yeast actin-binding protein is encoded by $S A C 6$, a gene found by suppression of an actin mutation. Science 243:231-233.

Birnboim HC, Doly J (1979): A rapid alkaline extraction procedure for screening recombinant plasmid DNA. Nucleic Acids Res 7:15131523.

Botstein D, Falco SC, Stewart SE, Brennan M, Scherer S, Stinchcomb DT, Struhl K, Davis RW (1979): Sterile host yeasts (SHY): A eukaryotic system of biological containment for recombinant DNA experiments. Gene 8:17-24.

Bradford M (1976): A rapid and sensitive method for the quantitation of microgram quantities of protein utilizing the principle of proteindye binding. Anal Biochem 72:248-254.

Burnette WN (1981): "Western blotting": Electrophoretic transfer of proteins from sodium dodecyl sulfate-polyacrylamide gels to unmodified nitrocellulose and radiographic detection with antibody and radioiodinated protein A. Anal Biochem 112:195-203.

Byers B (1981): Cytology of the yeast life cycle. In Strathern JN, Jones EW, and Broach JR (eds): "The Molecular Biology of the Yeast Saccharomyces: Life Cycle and Inheritance." Cold Spring Harbor, NY: Cold Spring Harbor Laboratory, pp 59-96.

Byers B, Goetsch L (1975): Behavior of spindles and spindle plaques in the cell cycle and conjugation of Saccharomyces cerevisiae. J Bacteriol 124:511-523.

Byers B, Goetsch L (1976a): A highly ordered ring of membraneassociated filaments in budding yeast. J Cell Biol 69:717-721.

Byers B, Goetsch L (1976b): Loss of the filamentous ring in cytokinesis-defective mutants of budding yeast. J Cell Biol 70:35a (Abstr.).

Cabib E, Roberts R, Bowers B (1982): Synthesis of the yeast cell wall and its regulation. Annu Rev Biochem 51:763-793.

Chant J, Corrado K, Pringle JR, Herskowitz I (submitted): The yeast $B U D 5$ gene, which encodes a putative GDP-GTP exchange factor, is necessary for bud-site selection and interacts with bud-formation gene $B E M 1$

Chen LB, Rosenberg S, Nadakavukaren KK, Walker ES, Shepherd EL, Steele GD Jr (1985): The cytoskeleton. In Springer TA (ed): "Hybridoma Technology in the Biosciences and Medicine." New York: Plenum Press, pp 251-267.

Drubin, DG, Miller KG, Botstein D (1988): Yeast actin-binding proteins: Evidence for a role in morphogenesis. J Cell Biol 107:25512561.

Haarer BK, Pringle JR (1987): Immunof luorescence localization of the Saccharomyces cerevisiae CDC12 gene product to the vicinity of the 10-nm filaments in the mother-bud neck. Mol Cell Biol 7:36783687.

Haarer BK, Lillie SH, Adams AEM, Magdolen V, Bandlow W, Brown SS (1990): Purification of profilin from Saccharomyces cerevisiae and analysis of profilin-deficient cells. J Cell Biol 110:105-114.

Haarer BK, Ketcham SR, Ford SK, Ashcroft DJ, and Pringle JR (submitted): The Saccharomyces cerevisiae $C D C 3, C D C 10, C D C 11$, and CDC12 genes encode a family of similar proteins.

Hartwell LH (1971): Genetic control of the cell division cycle in yeast. 
IV. Genes controlling bud emergence and cytokinesis. Exp Cell Res 69:265-276.

Hartwell LH, Unger MW (1977): Unequal division in Saccharomyces cerevisiae and its implications for the control of cell division. $J$ Cell Biol 75:422-435.

Hašek J, Rupeš I, Svobodová J, Streiblová E (1987): Tubulin and actin topology during zygote formation of Saccharomyces cerevisiae. J Gen Microbiol 133:3355-3363.

Hinnen A, Hicks JB, Fink GR (1978): Transformation of yeast. Proc Natl Acad Sci USA 75:1929-1933.

Holmes DS, Quigley $M$ (1981): A rapid boiling method for the preparation of bacterial plasmids. Anal Biochem 114:193-197.

Huffaker TC, Thomas JH, Botstein D (1988): Diverse effects of $\beta$ tubulin mutations on microtubule formation and function. J Cell Biol 106:1997-2010.

Hurn BAL, Chantler SM (1980): Production of reagent antibodies. Methods Enzymol 70:104-142.

Jacobs CW, Adams AEM, Szaniszlo PJ, Pringle JR (1988): Functions of microtubules in the Saccharomyces cerevisiae cell cycle. J Cell Biol 107:1409-1426.

Jamieson DJ, Rahe B, Pringle J, Beggs J (1991): A suppressor of a yeast splicing mutation ( $p r p 8-1$ ) encodes a putative ATP-dependent RNA helicase. Nature 349:715-717.

Kilmartin JV, Adams AEM (1984): Structural rearrangements of tubulin and actin during the cell cycle of the yeast Saccharomyces. J Cell Biol 98:922-933.

Kilmartin JV, Wright B, Milstein C (1982): Rat monoclonal antitubulin antibodies derived by using a new nonsecreting rat cell line. J Cell Biol 93:576-582.

Kim HB, Haarer BK, Pringle, JR (1991): Cellular morphogenesis in the Saccharomyces cerevisiae cell cycle: Localization of the CDC3 gene product and the timing of events at the budding site. $J$ Cell Biul 112:535-544.

Laemmli UK (1970): Cleavage of structural proteins during the assembly of the head of bacteriophage T4. Nature 227:680-685.

Lillie SH, Pringle JR (1980): Reserve carbohydrate metabolism in Saccharomyces cerevisiae: Responses to nutrient limitation. J Bacteriol 143:1384-1394.

Lillie SH, Haarer BK, Bloom L, Coleman KG, Pringle JR (submitted); Isolation and characterization of $C D C 3, C D C 11$, and $C D C 12$, three genes controlling morphogenesis in the Saccharomyces cerevisiae cell cycle.

Lipke PN, Taylor A, Ballou CE (1976): Morphogenic effects of $\alpha$-factor on Saccharomyces cerevisiae a cells. J Bacteriol 127:610-618.

Maniatis T, Fritsch EF, Sambrook J (1982): "Molecular Cloning, A Laboratory Manual.” Cold Spring Harbor, NY: Cold Spring Harbor Laboratory.

Messing J, Gronenborn B, Müller-Hill B, Hofschneider PH (1977) Filamentous coliphage M13 as a cloning vehicle: Insertion of a $\mathrm{Hin}$ -
dII fragment of the lac regulatory region in M13 replicative form in vitro. Proc Natl Acad Sci USA 74:3642--3646.

Novick P, Botstein D (1985): Phenotypic analysis of temperature-sensitive yeast actin mutants. Cell 40:405-416.

Paquin C, Adams J (1982): Isolation of sets of $\alpha, \alpha, a / \alpha, \alpha / a$, and $\alpha / \alpha$ isogenic strains in Saccharomyces cerevisiae. Curr Genet 6:21-24.

Pringle JR, Hartwell LH (1981): The Saccharomyces cerevisiae cell cycle. In Strathern JN, Jones EW, and Broach JR (eds): "The Molecular Biology of the Yeast Saccharomyces: Life Cycle and Inheritance." Cold Spring Harbor, NY: Cold Spring Harbor Laboratory, pp 97-142.

Pringle JR, Mor J-R (1975): Methods for monitoring the growth of yeast cultures and for dealing with the clumping problem. Methods Cell Biol 11:131-168

Pringle JR, Lillie SH, Adams AEM, Jacobs CW, Haarer BK, Coleman KG, Robinson JS, Bloom L, Preston RA (1986): Cellular morphogenesis in the yeast cell cycle. UCLA Symp Mol Cell Biol 33:47-80.

Pringle JR, Preston RA, Adams AEM, Stearns T, Drubin DG, Haarer BK, Jones EW (1989): Fluorescence microscopy methods for yeast. Methods Cell Biol 31:357-435.

Reid BJ, Hartwell LH (1977): Regulation of mating in the cell cycle of Saccharomyces cerevisiae. J Cell Biol 75:355-365.

Rüther U, Müller-Hill B (1983): Easy identification of cDNA clones. EMBO J 2:1791-1794.

Schekman R, Brawley V (1979): Localized deposition of chitin on the yeast cell surface in response to mating pheromone. Proc Natl Acad Sci USA 76:645-649.

Sherman F, Fink GR, Hicks JB (1986): "Methods in Yeast Genetics." Cold Spring Harbor, NY: Cold Spring Harbor Laboratory.

Slater ML, Bowers B, Cabib E (1985): Formation of septum-like structures at locations remote from the budding sites in cytokinesisdefective mutants of Saccharomyces cerevisiae. J Bacteriol 162: $763-767$.

Tkacz JS, MacKay VL (1979): Sexual conjugation in yeast: Cell surface changes in response to the action of mating hormones. J Cell Biol 80:326-333.

Towbin H, Staehelin T, Gordon J (1979): Electrophoretic transfer of proteins from polyacrylamide gels to nitrocellulose sheets: Procedure and some applications. Proc Natl Acad Sci USA 76: $4350-4354$

Trueheart J, Boeke JD, Fink GR (1987): Two genes required for cell fusion during yeast conjugation: Evidence for a pheromone-induced surface protein. Mol Cell Biol 7:2316-2328.

Wilkinson LE, Pringle JR (1974): Transient G1 arrest of S. cerevisiae cells of mating type $\alpha$ by a factor produced by cells of mating type $a$. Exp Cell Res 89:175-187.

Wittenberg C, Sugimoto K, Reed SI (1990): G1-specific cyclins of $S$. cerevisiae: Cell cycle periodicity, regulation by mating pheromone, and association with the p34 ${ }^{\text {CDC28 }}$ protein kinase. Cell 62:225-237. 